\title{
Predictive factors of head and neck squamous cell carcinoma patient tolerance to high-dose cisplatin in concurrent chemoradiotherapy
}

\author{
KENJI NAKANO ${ }^{1}$, YASUYOSHI SATO ${ }^{1}$, TAKASHI TOSHIYASU ${ }^{2}$, YUKIKO SATO ${ }^{3}$, LINA INAGAKI ${ }^{1}$, \\ JUNICHI TOMOMATSU ${ }^{1}$, TORU SASAKI ${ }^{4}$, WATARU SHIMBASHI ${ }^{4}$, HIROFUMI FUKUSHIMA ${ }^{4}$, \\ HIROYUKI YONEKAWA ${ }^{4}$, HIROKI MITANI ${ }^{4}$, KAZUYOSHI KAWABATA ${ }^{4}$ and SHUNJI TAKAHASHI $^{1}$ \\ Departments of ${ }^{1}$ Medical Oncology, ${ }^{2}$ Radiation Oncology, ${ }^{3}$ Pathology and ${ }^{4}$ Head and Neck Surgery, \\ Cancer Institute Hospital of the Japanese Foundation for Cancer Research, Tokyo 135-8550, Japan
}

Received June 2, 2015; Accepted November 16, 2015

DOI: $10.3892 / \mathrm{mco} .2015 .687$

\begin{abstract}
Although high-dose cisplatin is the standard regimen of concurrent chemoradiotherapy (CCRT) for locally advanced head and neck squamous cell carcinoma (HNSCC), varying levels of patient tolerance towards cisplatin have been reported, and the predictive factors of cisplatin tolerance remain to be elucidated. The present study retrospectively reviewed newly diagnosed HNSCC patients who received CCRT. Cisplatin $\left(80 \mathrm{mg} / \mathrm{m}^{2}\right)$ was administered every 3 weeks. The proportion of high-dose cisplatin-tolerant patients (cumulative cisplatin dose, $\geq 200 \mathrm{mg} / \mathrm{m}^{2}$ ) was determined, and the predictive factors of cisplatin tolerance were analyzed in a logistic regression analysis. Between June 2006 and March 2013, a total of 159 patients were treated with CCRT. The median follow-up time was 36.7 months. A total of 73 patients (46\%) tolerated a cumulative cisplatin dose $\geq 200 \mathrm{mg} / \mathrm{m}^{2}$; male gender [odds ratio (OR), 25.00; $\mathrm{P}=0.005]$ and high body surface area (BSA) $\left(>1.80 \mathrm{~m}^{2}\right.$; OR, 2.21; $\left.\mathrm{P}=0.032\right)$ were significantly predictive of high-dose cisplatin tolerance. The high-dose cisplatin-tolerant patients had a significantly higher complete response (CR) rate ( 82 vs. $67 \%, \mathrm{P}=0.045$ ); however, there were no significant between-group differences in the 3-year OS (79.5 vs. 81.2\%, $\mathrm{P}=0.59)$ or PFS (70.4 vs. $44.6 \%, \mathrm{P}=0.076)$ by cisplatin tolerance. In clinical practice, approximately one-half of the patients tolerated high-dose cisplatin in CCRT. Male gender and high BSA could be predictive of cisplatin tolerance.
\end{abstract}

\footnotetext{
Correspondence to: Dr Shunji Takahashi, Department of Medical Oncology, Cancer Institute Hospital of the Japanese Foundation for Cancer Research, Ariake 3-8-31, Tokyo 135-8550, Japan E-mail: s.takahashi-chemotherapy@jfcr.or.jp
}

Key words: head and neck squamous cell carcinoma, concurrent chemoradiotherapy, cisplatin, body surface area, aspiration pneumonia

\section{Introduction}

Concurrent chemoradiotherapy (CCRT) is the standard treatment strategy for locally advanced head and neck squamous cell carcinoma (HNSCC) (1). High-dose cisplatin is the most common CCRT regimen with evidence of its efficacy obtained in randomized clinical trials (2-4); however, due to severe adverse events, high-dose cisplatin is not applicable to all patients. Although the use of supportive care has improved the tolerability of cisplatin, the completion of a high-dose cisplatin CCRT regimen remains a difficult task. Additionally, although $100 \mathrm{mg} / \mathrm{m}^{2}$ per 3 weeks is the most certified dose of cisplatin in randomized clinical trials, this dose has not been approved in Japan.

Between 2000 and 2010, cetuximab, an anti-epidermal growth factor receptor (EGFR) antibody, was approved for the treatment of HNSCCs. Bio-radiotherapy (BRT) has also emerged as a new treatment option for locally advanced HNSCC (5). Although the superiority or non-inferiority of BRT compared to CCRT has not yet been established, BRT has been recognized as a feasible treatment option and it is becoming more widely used in clinical practice. In light of the effectiveness of BRT as an alternative treatment, when clinicians consider administering CCRT, they must select patients who can tolerate a high-dose cisplatin regimen. When making decisions regarding the appropriate treatment, it would be extremely helpful to know the predictive factors of cisplatin tolerability. The present study retrospectively explored the predictive factors of high-dose cisplatin tolerance.

\section{Materials and methods}

Patient enrollment. Subsequent to obtaining approval from our institutional review board, the clinical records of newly diagnosed HNSCC patients who received CCRT with a high-dose cisplatin regimen were retrospectively reviewed between June 2006 and March 2013 at the Cancer Institute Hospital of the Japanese Foundation for Cancer Research.

All the patients were diagnosed pathologically by histological specimens, and pathological specimens and reports were 
reviewed by a pathologist with a specialty in oncology (Yukiko Sato). For the evaluations of the primary lesions and lymph node metastases, computed tomography (CT) and magnetic resonance imaging (MRI) scans of the head and neck were performed in each case. For the identification of distant metastases and double cancers, chest CT scans and gastrointestinal fiberscopy were also performed for all patients.

Distant metastases were excluded from the indications for CCRT; however, patients with double cancers of the esophagus and/or stomach were allowed to receive CCRT when the double malignancies were limited to early stages that could be treated surgically or endoscopically prior or subsequent to CCRT. Patients who received induction chemotherapy or neck dissection prior to CCRT were included in the present analysis; however, cases of adjuvant CCRT following curative surgical resection were excluded. The indications for CCRT were discussed and decided upon by our institute's cancer board, which is comprised of medical oncologists, oncology radiologists, and head and neck surgeons.

Treatment. For the CCRT, cisplatin $80 \mathrm{mg} / \mathrm{m}^{2}$, which is the approved dose in Japan, was administered every 3 weeks for a total of three cycles. During the chemotherapy, the patients received appropriate antiemetics and hydration. Following the approval of the antiemetic and neurokinin 1 receptor antagonist aprepitant in Japan in December 2009, aprepitant or another neurokinin 1 receptor antagonist was administered perorally or intravenously to the patients who received CCRT. Elderly patients and those with reduced organ function received a reduced cisplatin dose according to the discretion of their physician. In cases in which one or more severe adverse events were observed during the CCRT, a skip, delay or dose reduction of the second or third cisplatin cycle was also allowed.

Radiotherapy was performed as 3-dimensional conformal radiotherapy (3D-CRT) or intensity-modified radiotherapy (IMRT) with the conventional fraction: 2-2.12 Gy/fraction, once a day, five times/week. Prophylactic percutaneous endoscopic gastrostomy (PEG) was performed unless particular reasons prohibited it (such as refusal by the patient or past history of gastrectomy).

Evaluation. The patient cisplatin tolerability was evaluated according to the cumulative cisplatin dose. Patients who received a cumulative dose of $\geq 200 \mathrm{mg} / \mathrm{m}^{2}$ were defined as tolerant to high-dose cisplatin, and patients who received a cumulative dose of $<200 \mathrm{mg} / \mathrm{m}^{2}$ were defined as intolerant to high-dose cisplatin. The rate of high-dose cisplatin-tolerant patients was identified, and predictive factors of high-dose cisplatin tolerance were investigated using Fisher's exact test and a logistic regression analysis. The associations between high-dose cisplatin tolerance and response, and between high-dose cisplatin tolerance and adverse events were also analyzed using Fisher's exact test.

The patient objective responses were evaluated by laryngopharyngeal endoscopy, CT scan and/or MRI, based on the Response Evaluation Criteria In Solid Tumours version 1.1 (6). Adverse events were documented based on the Common Terminology Criteria for Adverse Events version 4.0 (http:// evs.nci.nih.gov/ftp1/CTCAE/About.html).
For prognoses, progression-free survival (PFS) and overall survival (OS) were estimated by the Kaplan-Meier method. The association between high-dose cisplatin tolerance and prognoses was analyzed by Cox regression analyses.

For all statistical analyses, SPSS version 17.0 (SPSS, Inc., Chicago, IL, USA) was used. In all the analyses, $\mathrm{P}<0.05$ was considered to indicate a statistically significant difference, and in Fisher's exact test, two-sided P-values were evaluated.

\section{Results}

Patient characteristics. A total of 159 patients were enrolled in the analyses. The median follow-up time was 36.7 months. The patient characteristics are shown in Table I. The median age was 63 years old (range, 21-78 years), and the majority of patients $(86 \%)$ were male. Although over half the patients were stage IV, 30 (19\%) of the stage II patients were included in the study. The median body surface area (BSA) was $1.69 \mathrm{~m}^{2}$ (range, 1.30-2.14 $\mathrm{m}^{2}$ ), and the BSA values of $49(31 \%)$ patients were $>1.80 \mathrm{~m}^{2}$. The median body mass index (BMI) was $22.4 \mathrm{~kg} / \mathrm{m}^{2}$ (range, 14.9-29.8 kg/m²), and $114(72 \%)$ patients were within the range of $18.5-25.0 \mathrm{~kg} / \mathrm{m}^{2}$. Prior to the CCRT induction, $33(21 \%)$ patients received some anticancer treatments; 23 underwent neck dissection, and 10 received induction chemotherapy. As the induction chemotherapy regimen, docetaxel and cisplatin (TP) with 5-fluorouracil were used for 7 patients, TP for 2, and S-1 for 1 patient.

Treatment exposure. The patient treatment details are shown in Table II. Approximately one-half of the 159 patients completed three cycles of cisplatin, and 73 (46\%) patients reached cumulative cisplatin doses that were $\geq 200 \mathrm{mg} / \mathrm{m}^{2}$; i.e., they were high-dose cisplatin-tolerant. IMRT was performed for $64(40 \%)$ patients, and 3D-CRT was administered to $95(60 \%)$ patients. Two patients failed to complete the pre-planned radiation therapy; 1 discontinued $\mathrm{RT}$ due to a lethal infectious adverse event, and the other declined the continuation of the therapy. A neurokinin 1 receptor antagonist (aprepitant or fosaprepitant) was used for $138(87 \%)$ patients. PEG was conducted for 124 (78\%) patients, and 107 (67\%) patients received tube feeding during and/or following CCRT; this includes patients who received tube feeding from a nasogastric tube without PEG placement.

Predictive factors of high-dose cisplatin tolerance. The results of our analyses of predictive factors of high-dose cisplatin tolerance are shown in Table III. By Fisher's exact test, male gender [odds ratio (OR), 24.75; $\mathrm{P}<0.001$ ], high $\mathrm{BSA}\left(>1.80 \mathrm{~m}^{2}\right.$; OR, 3.17; $\mathrm{P}=0.002)$, high $\mathrm{BMI}(>25.0 ; \mathrm{OR}, 2.57 ; \mathrm{P}=0.027)$, and high creatinine clearance ( $>100 \mathrm{ml} / \mathrm{min}$; OR, $2.01 ; \mathrm{P}=0.048$ ) were significantly positive predictive factors of high-dose cisplatin tolerance. Of these factors, only male gender (OR, 25.00; $\mathrm{P}=0.005)$ and high $\mathrm{BSA}(\mathrm{OR}, 2.21 ; \mathrm{P}=0.032)$ were also significantly predictive of high-dose cisplatin tolerance by the logistic regression analysis.

Adverse events. The grade 3/4 adverse events during CCRT are shown in Table IV. One patient succumbed due to an adverse event on day 30 of the CCRT, due to systemic sepsis following diarrhea and severe renal failure. 
Table I. Characteristics of the patients with head and neck squamous cell carcinoma.

\begin{tabular}{|c|c|}
\hline Characteristics & Variables $(\mathrm{n}=159)$ \\
\hline \multicolumn{2}{|l|}{ Age, years } \\
\hline Median (range) & $63(21-78)$ \\
\hline$>60, \mathrm{n}(\%)$ & $91(58)$ \\
\hline \multicolumn{2}{|l|}{ Gender, n (\%) } \\
\hline Male & $136(86)$ \\
\hline Female & $23(14)$ \\
\hline \multicolumn{2}{|l|}{ ECOG performance status, $\mathrm{n}(\%)$} \\
\hline 0 & $148(93)$ \\
\hline 1 & $11(7)$ \\
\hline$\geq 2$ & $0(0)$ \\
\hline \multicolumn{2}{|l|}{ Body surface area, $\mathrm{m}^{2}$} \\
\hline Median (range) & $1.69(1.30-2.14)$ \\
\hline$>1.80, \mathrm{n}(\%)$ & $49(31)$ \\
\hline \multicolumn{2}{|l|}{ Body mass index, $\mathrm{kg} / \mathrm{m}^{2}$} \\
\hline Median (range) & $22.4(14.9-29.8)$ \\
\hline$<18.5, \mathrm{n}(\%)$ & $14(9)$ \\
\hline $18.5-25.0, \mathrm{n}(\%)$ & $114(72)$ \\
\hline$\geq 25.0, \mathrm{n}(\%)$ & $31(19)$ \\
\hline \multicolumn{2}{|l|}{ Primary site, n (\%) } \\
\hline Nasopharynx & $20(12)$ \\
\hline Oral cavity & $5(3)$ \\
\hline Oropharynx & $57(36)$ \\
\hline Hypopharynx & $57(36)$ \\
\hline Larynx & $14(9)$ \\
\hline Paranasal sinus/nasal cavity & $6(4)$ \\
\hline \multicolumn{2}{|l|}{ T stage, $\mathrm{n}(\%)$} \\
\hline $\mathrm{T} 1$ & $8(5)$ \\
\hline $\mathrm{T} 2$ & $92(58)$ \\
\hline T3 & $32(20)$ \\
\hline $\mathrm{T} 4$ & $27(17)$ \\
\hline \multicolumn{2}{|l|}{ N stage, n $(\%)$} \\
\hline No & $49(31)$ \\
\hline N1 & $22(14)$ \\
\hline $\mathrm{N} 2$ & $86(54)$ \\
\hline N3 & $2(1)$ \\
\hline \multicolumn{2}{|l|}{ Clinical stage, $\mathrm{n}(\%)$} \\
\hline II & $30(19)$ \\
\hline III & $33(21)$ \\
\hline IV & $96(60)$ \\
\hline \multicolumn{2}{|l|}{ Laboratory data, n (\%) } \\
\hline Albumin, $\geq 4.0 \mathrm{~g} / \mathrm{dl}$ & $107(67)$ \\
\hline High creatine clearance, $>100 \mathrm{ml} / \mathrm{min}$ & $60(38)$ \\
\hline Glycated hemoglobin, > upper normal limit & $19(11)$ \\
\hline \multicolumn{2}{|l|}{ Previous therapy, n (\%) } \\
\hline Absent & $126(79)$ \\
\hline Present & $33(21)$ \\
\hline Surgery (neck dissection) & $23(14)$ \\
\hline Induction chemotherapy & $10(6)$ \\
\hline \multicolumn{2}{|l|}{ Year of treatment, $\mathrm{n}(\%)$} \\
\hline 2006-2009 & $17(11)$ \\
\hline 2010 & $48(30)$ \\
\hline 2011 & $41(26)$ \\
\hline 2012 & $42(26)$ \\
\hline 2013 & $11(7)$ \\
\hline
\end{tabular}

Table II. Treatment details.

\begin{tabular}{lc}
\hline Treatments & Patients, $\mathrm{n}(\%)$ \\
\hline Radiation therapy & \\
Radiation style & \\
3D-CRT & $95(60)$ \\
IMRT & $64(40)$ \\
Radiation dosage, Gy & \\
$<60.0$ & $2(1)$ \\
$60.0-65.9$ & $6(4)$ \\
66 & $124(78)$ \\
$66.1-72.5$ & $27(17)$ \\
Chemotherapy & \\
Cisplatin cycles & \\
1 & \\
2 & $14(9)$ \\
3 & $65(41)$ \\
Cisplatin cumulative dose, $\mathrm{mg} / \mathrm{m}^{2}$ & $80(50)$ \\
$<160$ & \\
$160-199$ & $29(18)$ \\
$200-240$ & $57(36)$ \\
Total & $73(46)$ \\
\hline
\end{tabular}

The hematological adverse events tended to be more severe in the high-dose cisplatin intolerable patients; leukocytopenia and anemia in particular were observed at a significantly higher rate in the high-dose cisplatin-intolerant patients $(\mathrm{P}=0.024$ and $\mathrm{P}=0.039$, respectively). As for the non-hematological adverse events, increased creatinine and aspiration pneumonia were observed at a significantly high rate in the high-dose cisplatin-intolerant patients $(\mathrm{P}=0.016$ and $\mathrm{P}=0.001$, respectively). Mucositis was observed at a high rate regardless of the cisplatin tolerance.

Response and prognosis. At the time of the analyses, 21 fatalities and 62 adverse events were observed; these events included 46 progressive disease (31 local recurrences and/or 17 metastases), 16 secondary malignancies, 1 fatality due to an adverse event during CCRT, and 1 lethal event unrelated to malignancy following CCRT. The details of secondary malignancies are as follows: 7 esophageal carcinomas, 4 primary lung carcinomas, 1 cholangiocellular carcinoma, 1 pancreatic carcinoma, 2 colorectal carcinomas, 1 breast carcinoma, and 1 malignant lymphoma. One patient suffered from esophageal and lung carcinoma during the follow-up. Two patients succumbed due to secondary malignancies; one due to lung cancer and the other to malignant lymphoma.

Following the completion of CCRT, a complete response (CR) was certified in $118(74 \%)$ patients. Using the Kaplan-Meier method, the 3-year OS and PFS rates were 80.8 and $55.9 \%$, respectively. The CR rate of the high-dose cisplatin-tolerant patients was significantly higher than that of the high-dose cisplatin-intolerant patients (82 vs. 67\%, $\mathrm{P}=0.045)$. By Cox regression analyses, however, there were no significant differences in the OS or PFS rates; the 3-year OS values of the high-dose cisplatin-tolerant/intolerant 
Table III. Predictive factors of high-dose cisplatin tolerance.

\begin{tabular}{|c|c|c|c|c|}
\hline \multirow[b]{2}{*}{ Variable } & \multicolumn{2}{|c|}{ Fisher's exact test } & \multicolumn{2}{|c|}{ Logistic regression analysis } \\
\hline & Odds ratio & $\mathrm{P}$-value & Odds ratio & P-value \\
\hline Male & 24.75 & $<0.001$ & 25 & 0.005 \\
\hline Smoking history present & 1.35 & 0.46 & & \\
\hline Age, $\geq 61$ years & 0.61 & 0.15 & & \\
\hline Body surface area, $>1.80 \mathrm{~m}^{2}$ & 3.17 & 0.002 & 2.212 & 0.032 \\
\hline \multicolumn{5}{|l|}{ Body mass index, $\mathrm{kg} / \mathrm{m}^{2}$} \\
\hline$<18.5$ & 0.29 & 0.089 & & \\
\hline$\geq 25.0$ & 2.57 & 0.027 & & \\
\hline Stage 4 & 0.89 & 0.75 & & \\
\hline Albumin, $\geq 4 \mathrm{~g} / \mathrm{dl}$ & 1.77 & 0.13 & & \\
\hline Glycated hemoglobin, >upper normal limit & 1.10 & 1.00 & & \\
\hline High creatine clearance, $>100 \mathrm{ml} / \mathrm{min}$ & 2.01 & 0.048 & & \\
\hline Intensity-modified radiotherapy & 1.19 & 0.63 & & \\
\hline Treatment between 2012-2013 & 1.73 & 0.15 & & \\
\hline
\end{tabular}

Table IV. Grade 3/4 adverse events.

\begin{tabular}{|c|c|c|c|c|}
\hline \multirow[b]{2}{*}{ Adverse events } & \multirow[b]{2}{*}{ All patients, n (\%) } & \multicolumn{2}{|c|}{ Cisplatin cumulative dose, n (\%) } & \multirow[b]{2}{*}{ P-value } \\
\hline & & $\geq 200 \mathrm{mg} / \mathrm{m}^{2}$ & $<200 \mathrm{mg} / \mathrm{m}^{2}$ & \\
\hline \multicolumn{5}{|l|}{ Hematological } \\
\hline Leukocytopenia & $48(30)$ & $16(22)$ & $32(37)$ & 0.024 \\
\hline Neutropenia & $22(14)$ & $7(10)$ & $15(17)$ & 0.17 \\
\hline Anemia & $12(8)$ & $2(3)$ & $10(12)$ & 0.039 \\
\hline Thrombocytopenia & $2(1)$ & $0(0)$ & $2(2)$ & 0.50 \\
\hline \multicolumn{5}{|l|}{ Non-hematological } \\
\hline Mucositis & $41(26)$ & $16(22)$ & $25(29)$ & 0.36 \\
\hline Dysgeusia & $4(3)$ & $2(3)$ & $2(2)$ & 1.00 \\
\hline Xerostomia & $7(4)$ & $2(3)$ & $5(6)$ & 0.45 \\
\hline Dermatitis & $2(1)$ & $2(3)$ & $0(0)$ & 0.21 \\
\hline Liver function disorder & $8(5)$ & $3(4)$ & $5(6)$ & 0.73 \\
\hline Creatinine increased & $7(4)$ & $0(0)$ & $7(8)$ & 0.016 \\
\hline Electrolytes disorder & $16(10)$ & $8(11)$ & $8(9)$ & 0.80 \\
\hline Aspiration pneumonia & $20(13)$ & $2(3)$ & $18(20)$ & 0.001 \\
\hline
\end{tabular}

patients were 79.5 and $81.2 \%$, respectively (hazard ratio $=0.79, \mathrm{P}=0.59$ ), and the 3 -year PFS values of high-dose cisplatin-tolerant/intolerant patients were 70.4 and $44.6 \%$, respectively (hazard ratio $=0.58, \mathrm{P}=0.076$ ) (Fig. 1). Although the PFS tended to be longer in the high-dose cisplatin-tolerant patients, a statistically significant difference was not observed.

\section{Discussion}

For CCRT, the most well-confirmed chemotherapy regimen in randomized clinical trials (2-4) is high-dose cisplatin, $100 \mathrm{mg} / \mathrm{m}^{2}$ per 3 weeks. However, even with the extensive evidence of the efficacy of a high-dose cisplatin regimen, such a regimen has been not applied to all the HNSCC patients.
Additionally, although the feasibility of this regimen for Japanese patients was also evaluated and affirmed in a small study (7), the standard dose of cisplatin has been not approved in Japan.

The major reason for not administering a high-dose cisplatin regimen is its accompanying high risk of severe adverse events, resulting in the frequent non-completion of the cisplatin regimen. CCRT with high-dose cisplatin has been confirmed to improve patient responses and OS; however, its risk of severe adverse events is also increased (2-4). It was also reported that during long follow-ups, severe late toxicities are also problematic and affect long-term survival (8). However, dose reduction or discontinuation of high-dose cisplatin based on the risk of adverse events is not recommended, as the cumulative cisplatin dose and treatment 

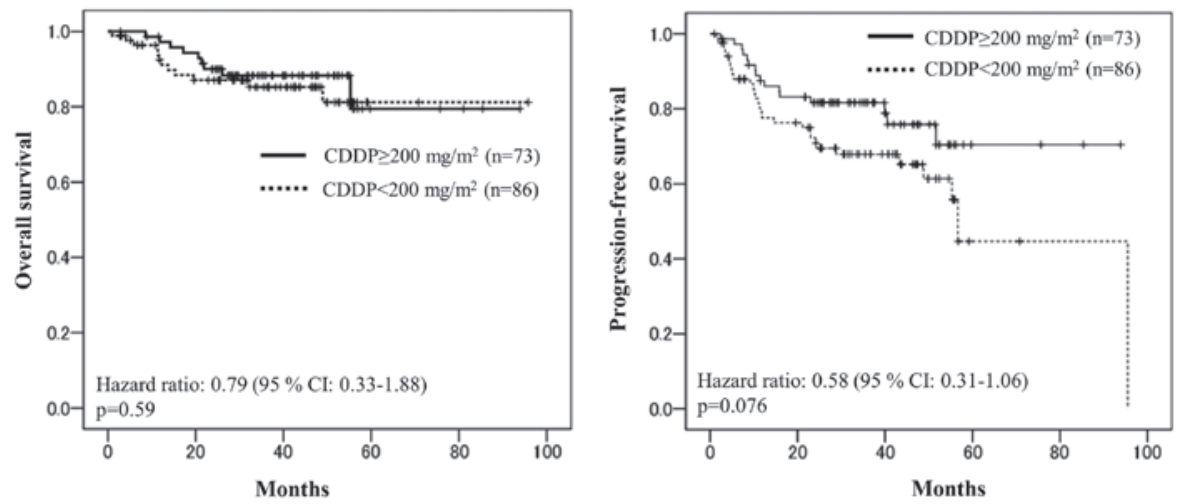

Figure 1. Cisplatin (i.e. CDDP) tolerance and prognoses of the 86 head and neck squamous cell carcinoma patients who received $<200 \mathrm{mg} / \mathrm{m}^{2} \mathrm{CDDP}$ vs. the 73 patients who received $\geq 200 \mathrm{mg} / \mathrm{m}^{2}$ CDDP.

cycles are correlated with the prognoses of HNSCC patients receiving CCRT (9).

Based on the review of the results of clinical trials reported until the early 2000s, the study by Ang (10) suggested that a cumulative cisplatin dose of $200 \mathrm{mg} / \mathrm{m}^{2}$ would be the threshold for patients to yield a beneficial antitumor effect from CCRT regardless of the schedule. Previous studies also suggest that a cumulative dose of $200 \mathrm{mg} / \mathrm{m}^{2}$ is the threshold to experience a benefit from CCRT $(11,12)$, and certain clinical trials set a total dose of $200 \mathrm{mg} / \mathrm{m}^{2}$ in their control group $(9,13)$. Based on these findings, the present study used the cumulative dose of $200 \mathrm{mg} / \mathrm{m}^{2}$ as the target dose.

In the present patient population, the rate of high-dose cisplatin-tolerant patients was $46 \%$; thus, approximately one-half of the patients did not reach the provisional cumulative cisplatin dose of $200 \mathrm{mg} / \mathrm{m}^{2}$ in the clinical practice. For high-dose cisplatin-intolerant patients, offering more feasible regimens other than high-dose cisplatin should be considered. Alternative regimens providing improved prognoses and less toxicity have been pursued, but as of 2000 , there were no other treatment regimens for CCRT that surpassed the effectiveness of high-dose cisplatin.

As a new treatment strategy, concomitant cetuximab treatment and radiotherapy (BRT) was certified to improve the prognoses of patients with locally advanced HNSCC compared to radiation only (5). BRT is recognized as a more feasible regimen compared to CCRT and is now widely indicated for locally advanced HNSCC patients. However, there is not enough evidence to conclude the superiority or non-inferiority of BRT to CCRT. Retrospective studies comparing the prognoses of patients who underwent CCRT to those who underwent BRT appear to show that the patients who received CCRT had a longer survival $(14,15)$, but it is likely that these studies have the limitation of selection bias, in which BRT may be preferably administered to patients with poor performance status, high risks or comorbidities. Recent prospective randomized trials comparing CCRT and BRT suggest that the prognoses afforded by these two treatment strategies are nearly equal $(16,17)$. However, in those prospective studies, the patients in the CCRT arms had relatively low compliance to the chemotherapy. It is quite possible that the equality of CCRT and BRT in these randomized studies was influenced by the differences in the treatment feasibility. To evaluate and decide whether CCRT with high-dose cisplatin or BRT is the better treatment strategy, high-dose cisplatin-tolerant patients must be identified, and the patient responses and prognoses following CCRT and BRT must be compared. As adding cetuximab to CCRT was shown to not contribute to an improvement of OS in the randomized trial RTOG 0522 (13), it is apparent that CCRT and BRT should not be administered to the same patients.

In current decisions of the indications for CCRT, in light of BRT as a feasible treatment option, we would like to predict the patients' tolerance to high-dose cisplatin, as well as their responses and prognoses. In the present retrospective study, male gender and BSA were significantly predictive for cisplatin tolerance. The male-female ratio of the HNSCC patients was highly biased, but considering the differences of the absolute number of patients, there is a clinical study that suggests female HNSCC patients tended to have poor prognoses (18). Differences of tolerability to high-dose cisplatin may be one of the reasons for the poor response among female HNSCC patients.

Associations between body weight and the incidence of several types of cancer have been described (19). Body weight is also suggested to be associated with prognoses in certain malignancies. Being overweight is suggested to be a poor prognostic factor in breast cancer patients (20), whereas for lung cancer patients and malignant lymphoma patients, there are certain studies indicating that overweight and even obesity is associated with a better prognoses $(21,22)$. HNSCC patients with high BMIs have been shown to be associated with longer survival $(23,24)$, and similar data were also reported for Japanese HNSCC patients (25).

In the present study, in addition to BSA, clinical parameters associated with the body mass and body weight, such as creatinine clearance and BMI were significant predictors of cisplatin tolerance by Fisher's exact test. Body weight and BMI reflect numerous patient background factors, such as nutrition, dietary habits, total mass of fat and/or muscle, and genetic factors. Forming conclusions regarding the associations between body weight and survival in HNSCC patients is difficult, but as a tool for evaluating the feasibility of treatments, body weight could be a useful factor as it is extremely easy to measure.

As for adverse events, high rates of hematological adverse events, renal dysfunction and aspiration pneumonia were 
observed in the cisplatin-intolerant patients. In previous studies, grade $3 / 4$ hematological adverse events were observed in $29-50 \%$ of patients receiving CCRT with high-dose cisplatin $(2-4,6)$. In the present series, there were no clear differences in hematological adverse events between the patients who were cisplatin-tolerant or -intolerant.

Aspiration pneumonia is a problematic adverse event among HNSCC patients, which is associated with dysphagia. Chen et al (26) examined the clinical courses of 595 HNSCC patients who received CCRT, and identified that the incidence of aspiration pneumonia during CCRT was $7 \%$. The risk of aspiration pneumonia remains high following CCRT completion. Hunter et al (27) reported that the cumulative incidence of aspiration pneumonia of oropharyngeal cancer patients following CCRT was $20 \%$ with the median follow-up time of 49 months. Mortensen et al (28) estimated the incidence of aspiration pneumonia in HNSCC patients treated with CCRT using the DAHANCA database, and reported the incidence rate of 29 per 1,000 person-years and the incidence proportion of $5.3 \%$ in the first year after radiotherapy. In the present study, the incidence of aspiration pneumonia was $12 \%$, which is relatively higher compared to the values in the previous studies. To complete a pre-planned cisplatin regimen, the prevention of aspiration pneumonia is extremely important. Weight loss and BMI were suggested to be associated with aspiration in patients treated for head and neck cancer (29).

The high-dose cisplatin-tolerant patients in the present study showed a high CR rate; however, there were no significant differences in the tolerant versus intolerant patient prognoses, in neither the PFS nor the OS. The present study has certain limitations regarding the evaluation of prognoses following CCRT: Short follow-up times, the stages included, and the lack of an evaluation of the patients' human papilloma virus (HPV) status. The median follow-up time in the study was 37.6 months, $<5$ years; which may not be enough time to evaluate long-term prognoses. The inclusion of stage II patients may confuse the evaluation of prognoses. HPV infection has been known to affect the incidence and prognosis of HNSCC, particularly oropharyngeal cancer (30). The present study included 57 (36\%) oropharyngeal cancer patients; however, the HPV status of these patients was not certified. In numerous prospective studies, HPV infection has been proven to be the better prognostic factor, as HPV-related HNSCC patients have good responses to radiotherapy and chemotherapy. In certain clinical trials, the influence of HPV status on prognosis was greater than that of the treatment interventions (31).

When planning treatment strategies for HNSCC patients, to improve patient prognoses and qualities of life, the appropriate treatment strategy should be selected based on the prognostic and predictive factors of each treatment. The present findings suggest that parameters associated with the patient body mass and weight may also be predictive factors of a high-dose cisplatin CCRT regimen. It would be worthwhile to further investigate such parameters when assessing the feasibility of and indications for CCRT.

\section{Acknowledgements}

The authors would like to thank all the staff members of the Departments of Head and Neck Surgery at the Cancer Institute
Hospital of the Japanese Foundation for Cancer Research for diagnosing and treating the patients enrolled in the present study.

\section{References}

1. Brizal DM and Esclamado R: Concurrent chemoradiotherapy for locally advanced, nonmetastatic, squamous carcinoma of the head and neck: Consensus, controversy and conundrum. J Clin Oncol 24: 2612-2617, 2006.

2. Adelstein DJ, Li Y, Adams GL, Wagner H Jr, Kish JA, Ensley DF, Schuller DE and Forastiere AA: An intergroup phase III comparison of standard radiation therapy and two schedules of concurrent chemothardiotherapy in patients with unresectable squamous cell head and neck cancer. J Clin Oncol 21: 92-98, 2003.

3. Al-Sarraf M, LeBlanc M, Giri PG, Fu KK, Cooper J, Vuong T, Forastiere AA, Adams G, Sakr WA, Schuller DE and Ensley JF: Chemoradiotherapy versus radiotherapy in patients with advanced nasopharyngeal cancer: Phase III Randomized Intergroup Study 0099. J Clin Oncol 16: 1310-1317, 1998.

4. Forastiere AA, Goepfert H, Maor M, Pajak TF, Weber R, Morrison W, Glisson B, Trotti A, Ridge JA, Chao C, et al: Concurrent chemotherapy and radiotherapy for organ preservation in advanced laryngeal cancer. N Engl J Med 349: 2091-2098, 2003.

5. Bonner JA, Harari PM, Giralt J, Azarnia N, Shin DM, Cohen RB, Jones CU, Sur R, Raben D, Jassem J, et al: Radiotherapy plus cetuximab for squamous-cell carcinoma of the head and neck. N Engl J Med 354: 567-578, 2006.

6. Eisenhauer EA, Therasse P, Bogaerts J, Schwartz LH, Sargent D, Ford R, et al: New response evaluation criteria in solid tumours: Revised RECIST guideline (version 1.1). Eur J Cancer 45: 226-247, 2009.

7. Zenda S, Onozawa Y, Tahara M, Kawashima M, Shikama N, Sasaki S and Boku N: Feasibility study of single agent cisplatin and concurrent radiotherapy in japanese patients with squamous cell carcinoma of the head and neck: Preliminary results. Jpn J Clin Oncol 37: 725-729, 2007.

8. Forastiere AA, Zhang Q, Weber RS, Maor MH, Goepfert H, Pajak TF, Morrison W, Glisson B, Trotti A, Ridge JA, et al: Long-term results of RTOG 91-11: A comparison of three nonsurgical treatment strategies to preserve the larynx in patients with locally advanced larynx cancer. J Clin Oncol 31: 845-852, 2013.

9. Nguyen-Tan PF, Zhang Q, Ang KK, Weber RS, Rosenthal DI, Soulieres D, Kim H, Silverman C, Raben A, Galloway TJ, et al: Randomized phase III trial to test accelerated versus standard fractionation in combination with concurrent cisplatin for head and neck carcinomas in the radiation therapy oncology group 0129 trial: Long-term report of efficacy and toxicity. J Clin Oncol 32: 3858-3866, 2014.

10. Ang KK: Concurrent radiation chemotherapy for locally advanced head and neck carcinoma: Are we addressing burning subjects? J Clin Oncol 22: 4657-4659, 2004.

11. Loong HH, Ma BB, Leung SF, Mo F, Hui EP, Kam MK, Chan SL, Yu BK and Chan AT: Prognostic significance of the total dose of cisplatin administered during concurrent chemoradiotherapy in patients with locoregionally advanced nasopharyngeal carcinoma. Radiother Oncol 104: 300-304, 2012.

12. Ghi MG, Paccagnella A, Floriani I and Garavaglia D: Concomitant chemoradiation in locally advanced head and neck squamous cell carcinoma: A literature-based meta-analysis on the platinum concomitant chemotherapy. J Clin Oncol 29 (Suppl): 5534, 2011.

13. Ang KK, Zhang QE, Rosenthal DI, Nguyen-Tan P, Sherman EJ, Weber RS, Galvin JM, Bonner JA, Harris J, El-Naggar AK, et al: Randomized phase III trial of concurrent accelerated radiation plus cisplatin with or without cetuximab for stage iii to iv head and neck carcinomas: RTOG 0522. J Clin Oncol 32: 2940-2950, 2014.

14. Koutcher L, Sherman E, Fury M, Wolden S, Zhang Z, Mo Q, Stewart L, Schupak K, Gelblum D, Wong R, et al: Concurrent cisplatin and radiation versus cetuximab and radiation for locally advanced head-and-neck cancer. Int J Radiat Oncol Biol Phys 81: 915-922, 2011.

15. Ley J, Mehan P, Wildes TM, Thorstad W, Gay HA, Michel L, Nussenbaum B, Trinkaus K and Adkins D: Cisplatin versus cetuximab given concurrently with definitive radiation therapy for locally advanced head and neck squamous cell carcinoma. Oncology 85: 290-296, 2013. 
16. Lefebvre JL, Pointreau Y, Rolland F, Alfonsi M, Baudoux A Sire C, de Raucourt D, Malard O, Degardin M, Tuchais C, et al: Induction chemotherapy followed by either chemoradiotherapy or bioradiotherapy for larynx preservation: The TREMPLIN randomized phase II study. J Clin Oncol 31: 853-859, 2013.

17. Ghi MG, Paccagnella A, Ferrari D, Foa P, Rocca MC, Verri E, Maiello E, Azzaello G, D'Ambrosio C, Casanova C, et al: A phase II-III study comparing concomitant chemoradiotherapy (CRT) versus cetuximab/RT (CET/RT) with or without induction docetaxel/cisplatin/5-fluorouracil (TPF) in locally advanced head and neck squamous cell carcinoma (LASCCHN): Efficacy results (NCT0186826). J Clin Oncol 31: suppl; abstr 6003, 2013.

18. Meyer F, Fortin A, Wang CS, Liu G and Bairati I: Predictors of severe acute and late toxicities in patients with localized head-and-neck cancer treated with radiation therapy. Int J Radiat Oncol Biol Phys 82: 1454-1462, 2012.

19. Bhaskaran K, Douglas I, Forbes H, dos-Santos-Silvia I, Leon DA and Smeeth L: Body-mass index and risk of 22 specific cancers: A population-based cohort study of 5.24 million UK adults. Lancet 384: 755-765, 2014

20. Sparano JA, Wang M, Zhao F, Stearns V, Martion S, Ligibel JA, Perez EA, Saphner T, Wolff AC, Sledge GW, et al: Obesity at diagnosis is associated with inferior outcomes in hormone receptor-positive operable breast cancer. Cancer 118: 5937-5946, 2012 .

21. Weiss L, Melchard T, Habringer S, Boekstegers A, Hufnagl C, Neureiter D, Hopfinger G, Greil R and Egle A: Increased body mass index is associated with improved overall survival in diffuse large B-cell lymphoma. Ann Oncol 25: 171-176, 2014

22. Dahlberg SE, Schiller JH, Bonomi PB, Sanler AB, Brahmer JR, Ramalingam SS and Johnson DH: Body mass index and its association with clinical outcomes for advanced non-small-cell lung cancer patients enrolled on Eastern cooperative oncology group clinical trials. J Thorac Oncol 8: 1121-1127, 2013.

23. Arthur AE, Peterson KE, Rozek LS, Tayloe JM, Light E, Chepeha DB, Hébert JR, Terrell JE, Wolf GT and Duffy SA; UM Head and Neck SPORE Program: Pretreatment dietary patterns, weight status and head and neck squamous cell carcinoma prognosis. Am J Clin Nutr 97: 360-368, 2013.
24. McRackan TR, Watkins JM, Herrin AE, Garrett-Mayer EM, Sharma AK, Day TA and Gillespie MB: Effect of body mass index on chemoradiation outcomes in head and neck cancer. Laryngoscope 118: 1180-1185, 2008.

25. Takenaka Y, Takemoto N, Nakahara S, Yamamoto Y, Yasui T, Hanamoto A, Fukusumi T, Michiba T, Cho H, Yamamoto M and Inohara $\mathrm{H}$ : Prognostic significance of body mass index before treatment of head and neck cancer. Head and Neck 37: 1518-1523, 2015.

26. Chen SW, Yang SN, Liang JA and Lin FJ: The outcome and prognostic factors in patients with aspiration pneumonia during concurrent chemoradiotherapy for head and neck cancer. Eur J Cancer Care (Engl) 19: 631-635, 2010

27. Hunter KU, Lee OE, Lyden TH, Haxer MJ, Feng FY, Schipper M, Worden F, Prince ME, McLean SA, Wolf GT, et al: Aspiration pneumonia after chemo-intensity-modulated radiation therapy of oropharyngeal carcinoma and its clinical and dysphagia-related predictors. Head and Neck 36: 120-125, 2014.

28. Mortensen HR, Jensen K and Grau C: Aspiration pneuonia in patients treated with radiotherapy for head and neck cancer. Acta Oncologica 52: 270-276, 2013.

29. Ottosson S, Lindblom U, Wahlberg P, Nilsson P, Kjellén E, Zackrisson B, Levring Jäghagen $\mathrm{E}$ and Laurell $\mathrm{G}$ : Weight loss and body mass index in relation to aspiration in patients treated for head and neck cancer: A long-term follow-up. Support Care Cancer 22: 2361-2369, 2014.

30. Ang KK, Harris J, Wheeler R, Weber R, Rosenthal DI, Nguyen-Tân PF, Westra WH, Chung CH, Jordan RC, Lu C, et al: Human papillomavirus and survival of patients with oropharyngeal cancer. N Engl J Med 363: 24-35, 2010.

31. Posner MR, Lorch JH, Goloubeva O, Tan M, Schumaker LM, Sarlis NJ, Haddad RI and Cullen KJ: Survival and human papillomavirus in oropharynx cancer in TAS 324: A subset analysis from an international phase III trial. Ann Oncol 22: 1071-1077, 2011. 